\title{
Biosynthesis of Iron Nanoparticles Using Tie Guanyin Tea Extract for Degradation of Bromothymol Blue
}

\author{
Haiyan Xin, Xin Yang, Xiaoli Liu, Xueping Tang, Lianjin Weng, and Yuanyuan Han
}

Fujian Provincial Key Laboratory of Biochemical Technology, College of Chemical Engineering, Huaqiao University, No. 668 Jimei Avenue, Xiamen 361021, China

Correspondence should be addressed to Xin Yang; yangxin@hqu.edu.cn

Received 30 June 2016; Revised 18 November 2016; Accepted 24 November 2016

Academic Editor: Marco Rossi

Copyright (C) 2016 Haiyan Xin et al. This is an open access article distributed under the Creative Commons Attribution License, which permits unrestricted use, distribution, and reproduction in any medium, provided the original work is properly cited.

Facile synthesis of zero-valent iron nanoparticles has been developed using Tie Guanyin tea extract as reducing and stabilizing agent. The characterization carried out by UV-Vis, SEM, TEM, XRD, and FTIR techniques has identified the successful synthesis of the zero-valent iron nanoparticles. It is evident from the TEM result that spherical zero-valent iron nanoparticles with average size of $6.58 \pm 0.76 \mathrm{~nm}$ have been obtained through biological method in this study. FTIR spectrum demonstrates that the polyphenols play an important role in the synthetic process. Diffraction peak at $2 \theta$ of $44.9^{\circ}$ and $49.1^{\circ}$ in XRD spectrum explains the existence of the iron nanoparticles. Additionally, effect of concentration of iron nanoparticles and concentration of bromothymol blue on the kinetic rate constants during the degradation process was studied.

\section{Introduction}

Recent years have witnessed the serious shortage of clean and safe water in China, because the water resources are facing severe challenges from environment pollution due to the urbanization, industrialization, agriculture, and mining activities $[1,2]$. Especially the dyes present imminent threat to water quality of the big and medium-sized cities with the continuous development of printing and dyeing industry $[3,4]$. The disposal of dyeing wastewater has thus attracted more and more attention in order to achieve sustainable development [5].

Nanotechnology has recently attracted intensive attention from the industrial circle and academia for its applications in a variety of fields. As reported, nanomaterials can exert their unique performance in widespread areas, such as medical care [6], food-related uses [7], biological sensing [8], and environmental remediation [9], using as antibacterial agent, adsorbent, and efficient catalyst, due to its peculiar physical and chemical properties $[3,10,11]$. Among reported metal nanoparticles, the study of iron nanoparticles is one of the most interesting research areas in recent years. Iron nanoparticles refer to the zero-valent iron particles with particle size in the range of 1 to $100 \mathrm{~nm}$. Zero-valent iron can reduce the metal ions that are located behind it in the periodic table of elements, owing to its intrinsic strong reducing ability [12]. Additionally, it can also degrade the toxic refractory organic compounds, by decomposing macromolecular substances into smaller molecule, transforming the chemicals with difficult biochemical degradation into the materials with easy biochemical treatment [13-15]. Namely, the zero-valent iron can be widely applied in wastewater treatment and biocatalysis [16]. To date, physical and chemical methods are two general approaches with regard to the synthesis of iron nanoparticles. The physical methods mainly include the high-energy ball-milling technique, physical vapor deposition method, metal vapor synthesis, sputtering, vacuum evaporation method, and mechanical alloying method. However, these well-established tools are critical of the instrument and equipment and lack effective way to control the morphology of metal nanoparticles. Comparatively, the chemical protocol to fabricate metal nanoparticles has drawn more attention due to its flexibility and easy operation. The chemical synthesis of nanoparticles is usually divided into chemical reduction method, high temperature pyrolysis method, microemulsion method, and electrochemical method [17]. If these techniques can be achieved successfully, it is usually inevitable to use poisonous chemical reagent 
(reducing agent, protective agent), like sodium borohydride, hydrazine hydrate, hexadecyltrimethylammonium bromide (CTAB) and polyethylene glycol (PEG), and so forth [18-20]. As a consequence, it can bring about a certain degree of environmental concerns, which does not conform to the green chemistry principles and the sustainable development of our society.

Since the inception of the new century, biosynthesis of nanoparticles as an emerging highlight of nanotechnology has received increasing attention due to a growing need to develop environmentally benign technologies in materials synthesis [21-24]. For example, a great deal of effort has been put into green synthesis of metal nanoparticles, using microorganisms, chitosan, cellulose nanocrystal, and plants [25-32]. Sastry and coworkers attained biosynthesis of metal nanoparticles by plant leaf extract [33,34]. We demonstrated the formation of $\mathrm{Au}, \mathrm{Ag}$, and $\mathrm{Pd}$ nanoparticles by biomass or plant extract [35-37]. The aforementioned synthetic protocol exemplifies the promising application of the plant bioresource for synthesis of metal nanoparticles. However, few studies have been reported on the green synthesis of zero-valent iron nanoparticles using the biomass in nature.

In this work, greenly synthesized zero-valent iron nanoparticles (GZVINPs) were synthesized with the extract of Tie Guanyin tea, which is semifermented tea and abundantly available in Fujian, China. The active components of the Tie Guanyin tea extract are the polyphenols and flavonoids, which have identified that conjugated $\pi$ electron system of molecules can make the hydroxyl groups donate electrons to free radicals and thus better antioxidant ability [38]. The purposes of the current work are as follows: (i) synthesis of zero-valent iron nanoparticles (ZVINPs) with Tie Guanyin tea extract, which is native to Fujian, China, (ii) characterizations of the ZVINPs employed to analyze its morphology, size, and structure, and (iii) application of iron nanoparticles for the catalytic degradation of bromothymol blue.

\section{Materials and Methods}

2.1. Green Synthesis of GZVINPs. Tie Guanyin tea extract was obtained by heating $20 \mathrm{~g} / \mathrm{L}$ Tie Guanyin tea to $80^{\circ} \mathrm{C}$ with mechanical agitation followed by vacuum filtration. Subsequently, $0.05 \mathrm{M} \mathrm{FeCl}_{3}$ was added to $20 \mathrm{~g} / \mathrm{L}$ Tie Guanyin tea extract in a $1: 2$ volume ratio. The resulting solution was then incubated in a $60^{\circ} \mathrm{C}$ water bath for $1 \mathrm{~h}$ to attain GZVINPs.

2.2. Preparation of Bromothymol Blue and $\mathrm{H}_{2} \mathrm{O}_{2}$ Solutions. In this experiment, different concentrations of bromothymol blue $(100,150,250,400$, and $500 \mathrm{mg} / \mathrm{L})$ were prepared by dissolving appropriate amount of bromothymol blue in deionized water. Separately, a $2 \% \mathrm{H}_{2} \mathrm{O}_{2}$ solution was obtained from an unstabilized $30 \% \mathrm{H}_{2} \mathrm{O}_{2}$ solution by diluting with deionized water.

2.3. Characterization of GZVINPs. The UV-Vis spectra of the produced dispersions were recorded at different wavelengths on a Lambda 950 spectrophotometer (PerkinElmer, USA). The FTIR spectra of the powdered GZVINPs were collected

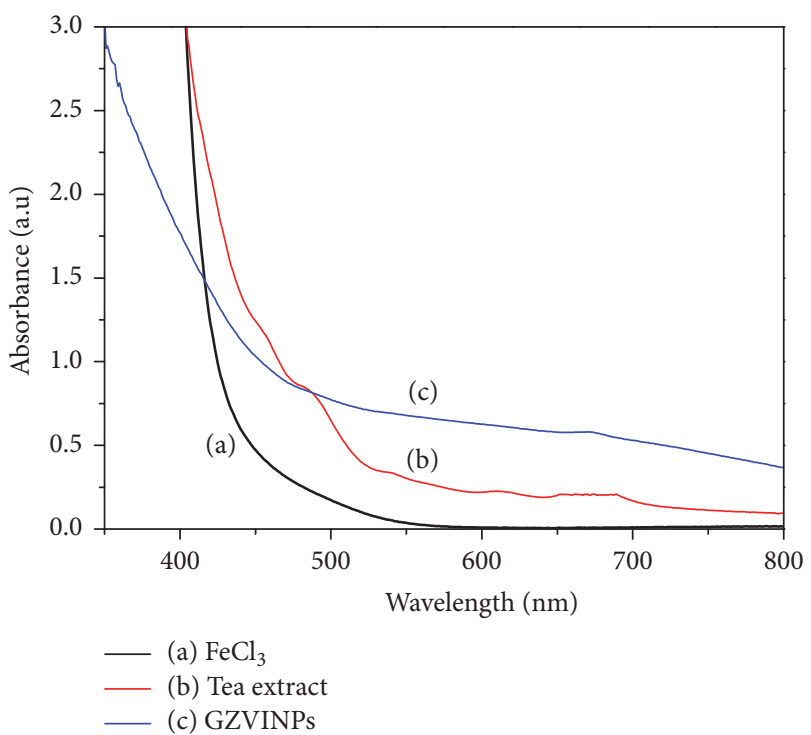

Figure 1: The UV spectra of (a) $\mathrm{FeCl}_{3}$, (b) tea extract, and (c) GZVINPs.

using iS50 (Thermo Fisher) infrared spectrophotometer. For this, the sheer slices of samples were prepared by mixing $1 \%(\mathrm{w} / \mathrm{w}$ ) sample with $100 \mathrm{mg} \mathrm{KBr}$. The XRD analysis of the GZVINPs was performed using X-ray diffraction analyzer (SmartLab, Rigaku, Japan) Cu Ka radiation $(\lambda=1.54 \AA)$ in a scanning range from $10^{\circ}$ to $80^{\circ} 2 \theta$ at a scanning rate of $3^{\circ} \mathrm{min}^{-1}$. Before observation with SEM, the sample was diluted in ethanol solution and ultrasonicated for $15 \mathrm{~min}$. Scanning electron microscope HITACHI SU8000 was used with accelerating voltage of $3000 \mathrm{~V}$ and 60000 magnifications. Prior to observation with TEM, the sample was diluted in ethanol solution and ultrasonicated for $25 \mathrm{~min}$. One drop of ethanol slurry was dropped on carbon coated copper grid and left for vacuum drying and then the prepared sample was observed using TEM. Pictures of the sample were taken with Tecnai F30 (FEI, Philips, Netherlands) TEM, operated at $300 \mathrm{kV}$.

2.4. Batch Experiments. All the degradation of bromothymol blue experiments was carried out at room temperature. The UV-Vis absorbance was read at $\lambda_{\max }=431 \mathrm{~nm}$ for bromothymol blue using PerkinElmer UV WinLab. The concentrations were determined which were dependent on the standard curves of bromothymol blue. Additionally, the blank experiment was performed just only with $\mathrm{H}_{2} \mathrm{O}_{2}$. Batch experiments were conducted to degrade the bromothymol blue by using the catalysts synthesized with Tie Guanyin tea extract from aqueous medium. For this experiment, the quartz cuvette was used as the reaction vessel for all experiments. $3 \mathrm{~mL}$ of $500 \mathrm{mg} / \mathrm{L}$ bromothymol and $2 \% \mathrm{H}_{2} \mathrm{O}_{2}$ were added into a quartz cuvette. The iron source was injected quickly into the cuvette which was in the spectrophotometer. Then scans were started instantly and the mixed solution remained untouched until completion. Various concentrations of GZVINPs as $0.06,0.12,0.33,0.5$, and $0.66 \mathrm{mM}$ were used for this experiment to determine their removal 


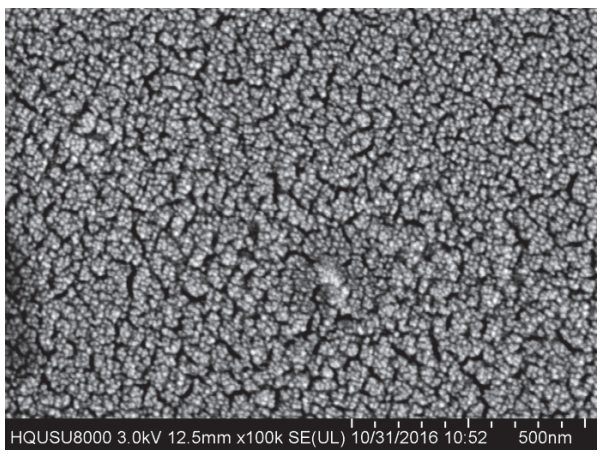

(a)

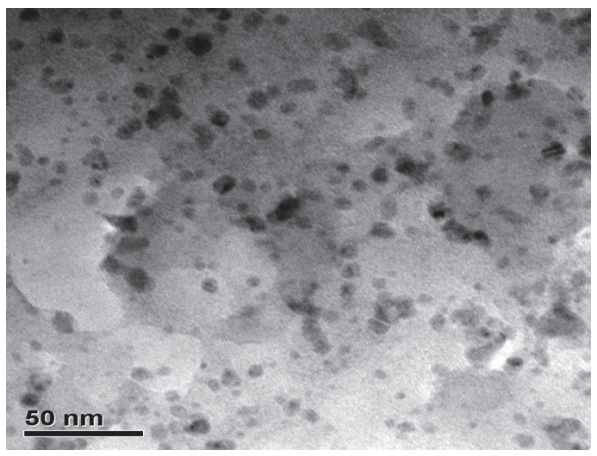

(b)

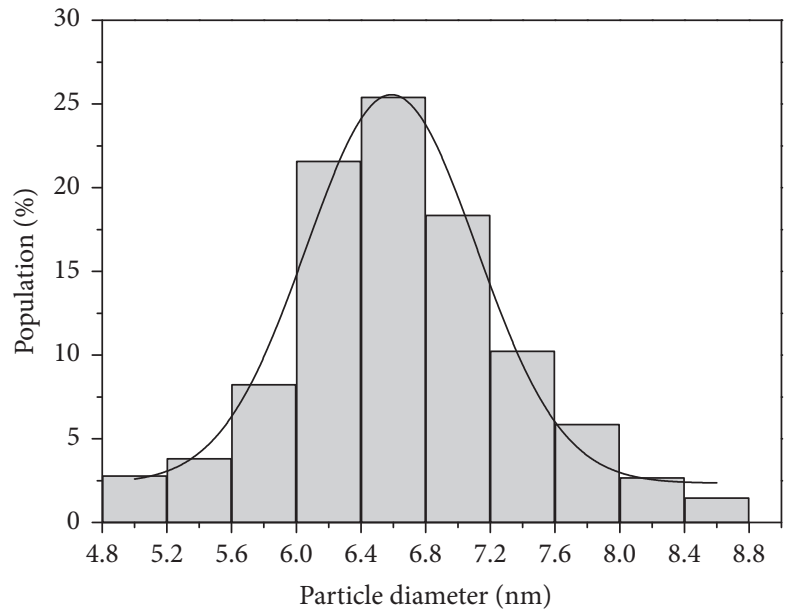

(c)

Figure 2: (a) The SEM image, (b) TEM image of the GZVINPs synthesized with Tie Guanyin tea extract, and (c) population distribution of the nanoparticles. Average diameter is $6.58 \pm 0.76 \mathrm{~nm}$.

efficiency. Similarly, the effects of different concentrations $(100.0,150.0,250.0,400.0$, and $500.0 \mathrm{mg} / \mathrm{L})$ of bromothymol blue were also investigated.

\section{Results and Discussion}

When Tie Guanyin tea extract and aqueous $\mathrm{FeCl}_{3}$ solution were mixed, the color of the reaction mixture instantaneously turned dark brown from yellow. Meanwhile, we could observe that visually black precipitates appeared in beaker. The formation of GZVINPs was further explained by measuring their absorbance with UV-Vis spectrophotometer over the range from 350 to $800 \mathrm{~nm}$ (Figure 1). For $\mathrm{FeCl}_{3}$ solution, there was no sharp absorption between 550 and $800 \mathrm{~nm}$, while the GZVINPs slurry had obvious absorption at a higher wavelength, and also it was drastically different from the other two after $490 \mathrm{~nm}$.

Figure 2 shows the SEM and TEM images of the synthesized GZVINPs. It is obvious to see that the iron nanoparticles exhibit spherical shape in nature. TEM characterization (Figure 2(b)) further illustrates the uniform distribution of the spherical nanoparticles and the average particle size is about $6.58 \pm 0.76 \mathrm{~nm}$ (Figure 2(c)).

FTIR analysis was applied to evaluate the vibrational characteristics of the possible biomolecules attached with the iron nanoparticles. FTIR spectrum of Tie Guanyin tea displays stretching vibrations at $1,634 \mathrm{~cm}^{-1}$ for $\mathrm{C}=\mathrm{C}$ and $3382 \mathrm{~cm}^{-1}$ for $\mathrm{O}-\mathrm{H}$, and $\mathrm{C}-\mathrm{H}$ and $\mathrm{C}-\mathrm{N}$ adsorption bands at 2920 and $1367 \mathrm{~cm}^{-1}$. In comparison, the FTIR spectrum of iron nanoparticles shows large stretch of $\mathrm{O}-\mathrm{H}$ group at $3410 \mathrm{~cm}^{-1}, \mathrm{C}-\mathrm{H}$ at $2923 \mathrm{~cm}^{-1}, \mathrm{C}=\mathrm{C}$ at $1594 \mathrm{~cm}^{-1}$, and C-O-C and $\mathrm{C}-\mathrm{N}$ at 1039 and $1396 \mathrm{~cm}^{-1}$ (Figure 3(a)), which is fitted well to the spectrum of tea extract. Based on the analysis, the bonding of the oxidized polyphenols on the surface of GZVINPs is examined. Consequently, it is speculated that polyphenols may function as both reducing and capping agent in the synthetic process.

XRD analysis was carried out to investigate the patterns of the synthesized iron nanoparticles in the sample (Figure $3(\mathrm{~b})$ ). The XRD analysis illustrated that several obvious peaks at about $44.9^{\circ}$ and $49.2^{\circ}$ show the presence of zerovalent iron $[3,39]$, while the peaks at around $35.5^{\circ}$ and $20-$ $35^{\circ}$ were attributed to magnetite $\left(\mathrm{Fe}_{3} \mathrm{O}_{4}\right)$ and iron hydroxides $(\mathrm{FeOOH})$, respectively [40], whereas the peak at about $17.6^{\circ}$ was identified as the ingredient in polyphenols/caffeine of the tea extract [18].

To evaluate the degradation potential of iron nanoparticles, batch experiments were carried out. As shown in Figure 4, bromothymol blue could hardly be degraded in the presence of $\mathrm{H}_{2} \mathrm{O}_{2}$ without any catalyst, while less than $10 \%$ of 


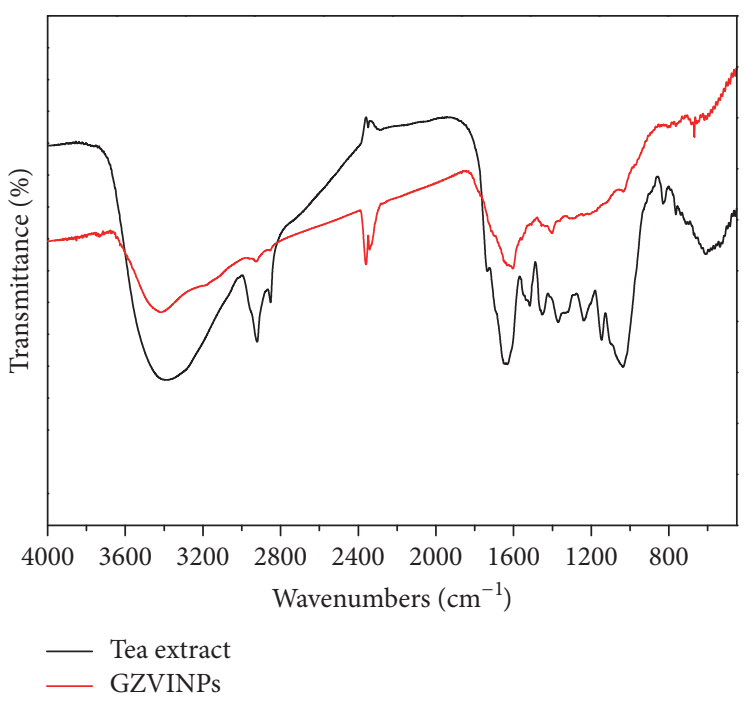

(a)

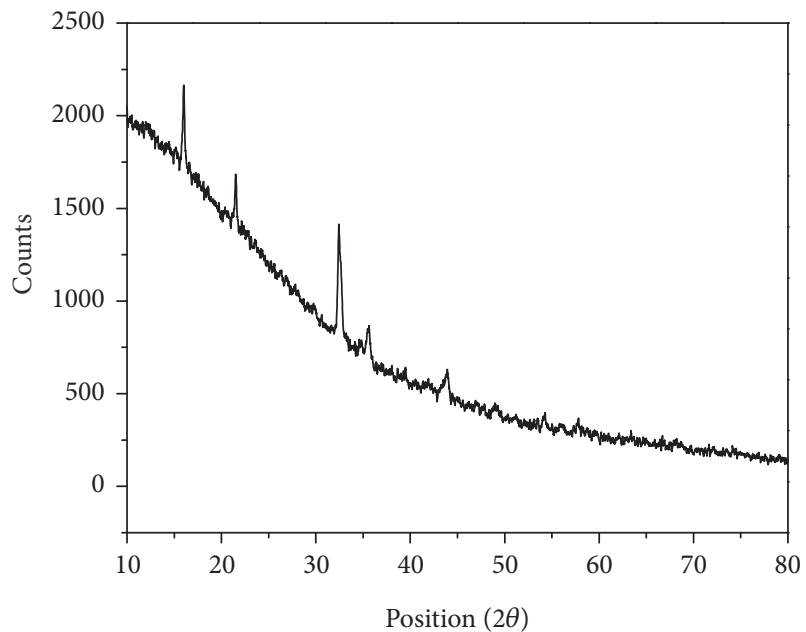

(b)

FIGURE 3: FTIR spectrum (a) and XRD pattern of GZVINPs synthesized with Tie Guanyin tea extract (b).

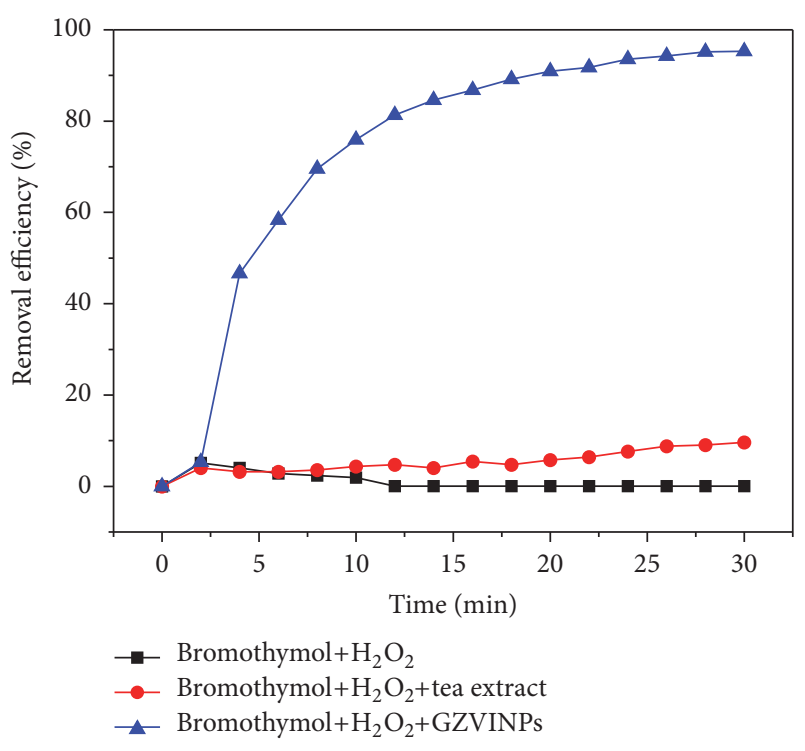

FIGURE 4: The degradation of bromothymol blue by tea extract and GZVINPs and in the absence of catalyst.

bromothymol blue was degraded for the tea extract and more than $90 \%$ was degraded by GZVINPs.

Moreover, it is clearly observed from Figure 5 that the maximum absorbance at $431 \mathrm{~nm}$ decreases along with every scanning time in the UV-Vis spectrum and the removal of bromothymol blue proceeds almost instantaneously, with more than $90 \%$ of the bromothymol blue being removed within $15 \mathrm{~min}$ using 0.33 or $0.5 \mathrm{mM}$ GZVINPs. The asprepared GZVINPs took much less time for the degradation of the bromothymol blue compared with the result ( $\sim 60 \mathrm{~min})$ in the reported literature [39]. Interestingly, the removal efficiency with $0.5 \mathrm{mM}$ GZVINPs is similar to $0.33 \mathrm{mM}$ as demonstrated by the results of Figure 5(d). Overall, it can be
TABLE 1: Rates constants of degradation of bromothymol blue with GZVINPs catalyzed $\mathrm{H}_{2} \mathrm{O}_{2}$.

\begin{tabular}{lccc}
\hline Curve in Figure 6 & $\begin{array}{c}\text { GZVINPs } \\
(\mathrm{mM})\end{array}$ & $\begin{array}{c}\text { Rate } \\
\left(\mathrm{min}^{-1}\right)\end{array}$ & $R^{2}$ \\
\hline (a) & 0.06 & 0.04353 & 0.98308 \\
(b) & 0.12 & 0.08437 & 0.97672 \\
(c) & 0.33 & 0.2019 & 0.91499 \\
(d) & 0.5 & 0.14225 & 0.97781 \\
(e) & 0.66 & 0.13645 & 0.96021 \\
\hline
\end{tabular}

inferred that higher GZVINPs concentrations accelerate the oxidation of the bromothymol blue.

To confirm the degradation of bromothymol by assynthesized iron nanoparticles, the experimental data were fitted well to pseudo-first-order reaction kinetic models. The finding was consistent with the report in the references [32]. A line could be drawn to obtain the rate constants by plotting $\ln \left(C_{t} / C_{0}\right)$ versus reaction time. The results were shown in Figure 6 . The graph illustrated how the iron nanoparticles concentration affected the degradation of bromothymol blue over time in the presence of $2 \% \mathrm{H}_{2} \mathrm{O}_{2}$ and $0.06,0.12,0.33,0.5$, and $0.66 \mathrm{mM}$ GZVINPs, respectively. In contrast, $0.33 \mathrm{mM}$ GZVINPs catalyzed $\mathrm{H}_{2} \mathrm{O}_{2}$ generated the highest catalytic reactivity. The rate constants increased significantly from $0.04353 \mathrm{~min}^{-1}$ at $0.06 \mathrm{mM}$ GZVINPs to $0.20190 \mathrm{~min}^{-1}$ at $0.33 \mathrm{mM}$ GZVINPs, whereas a decrease was observed when the concentration of GZVINPs exceeded $0.33 \mathrm{mM}$ (Table 1). The degradation of the bromothymol blue was proved to have obvious relationships with the concentration of the iron nanoparticles. Therefore, $0.33 \mathrm{mM}$ GZVINPs was considered adequate to achieve the best removal efficiency and used for next experiments.

In order to study the effect of the concentration of bromothymol blue on the kinetic rate constants, $0.33 \mathrm{mM}$ 


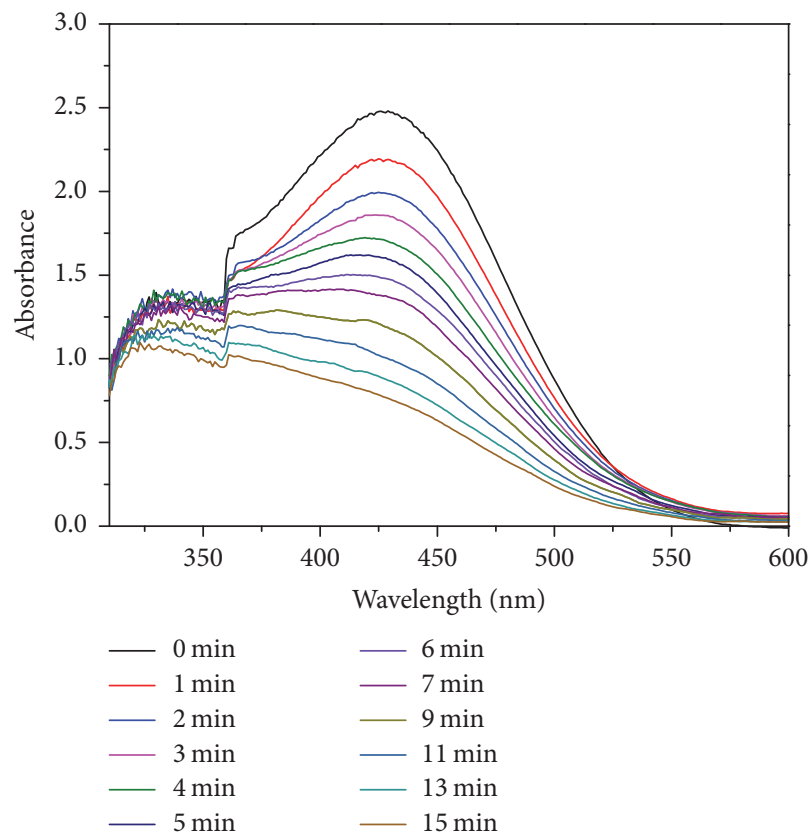

(a)

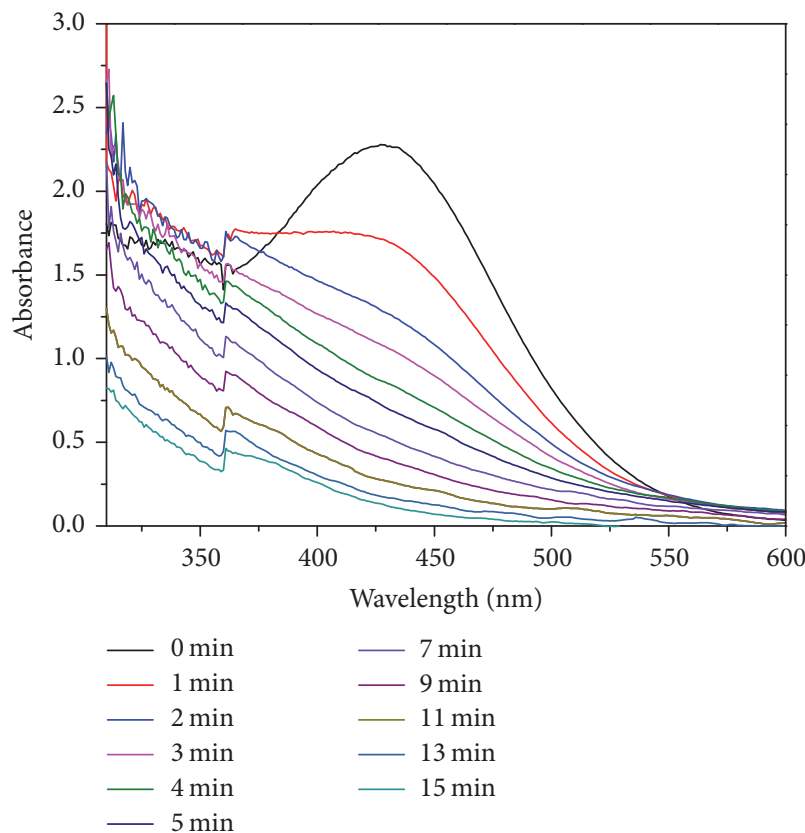

(c)

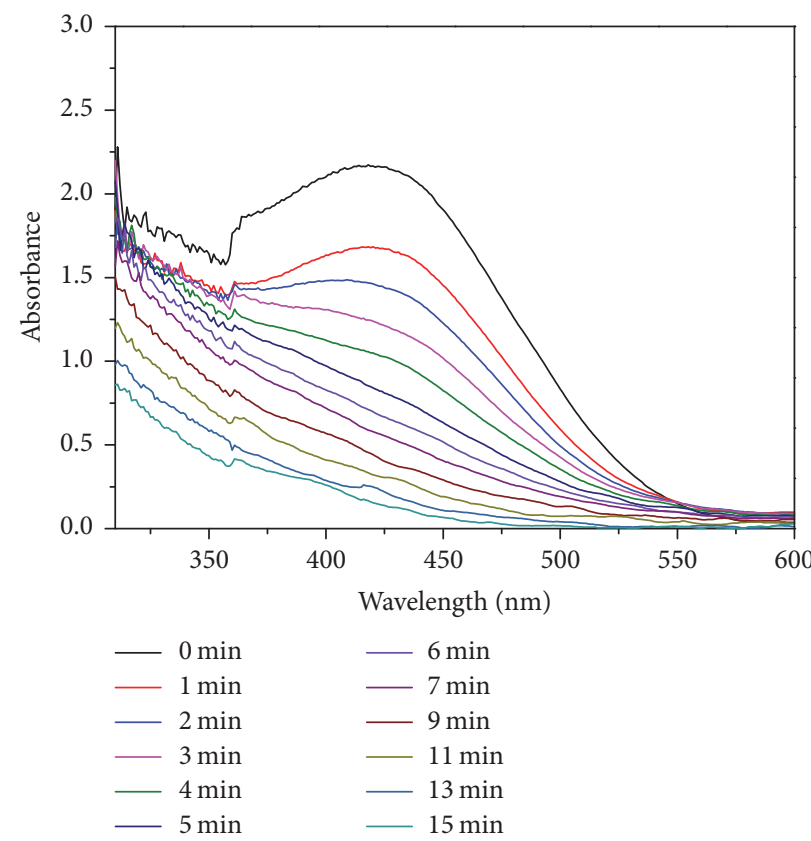

(b)

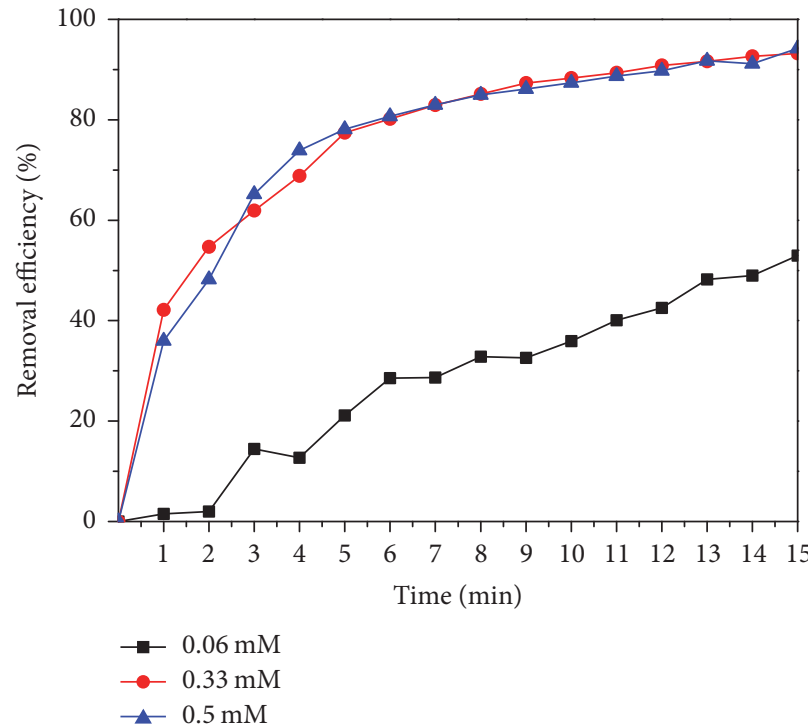

(d)

FIGURE 5: The UV-Vis spectra of bromothymol blue over time with different concentration of GZVINPs, (a) $0.06 \mathrm{mM}$, (b) $0.33 \mathrm{mM}$, (c) $0.5 \mathrm{mM}$, and $(\mathrm{d})$, and the degradation of bromothymol blue.

GZVINPs was used for $100,150,250,400$, and $500 \mathrm{mg} / \mathrm{L}$ bromothymol blue. As seen in Figure 7, increase of the bromothymol blue concentration led to rapid degradation before the concentration came to $150 \mathrm{mg} / \mathrm{L}$, but the rate constants decreased gradually after that (Table 2). The results indicated that high bromothymol concentration was not beneficial to the decomposition of $\mathrm{H}_{2} \mathrm{O}_{2}$ and the formation of hydroxyl radicals, leading to slowdown of degradation speed.

\section{Conclusions}

A facile one-pot green method was developed to synthesize the GZVINPs successfully using the Tie Guanyin tea extract and $\mathrm{FeCl}_{3}$ solution without additional chemical agents. The tea polyphenols act as both reducing and capping agents that prolong the lifetime of the catalyst. Importantly, the asprepared GZVINPs showed high activity for bromothymol blue degradation with more than $90 \%$ of the dye removal 


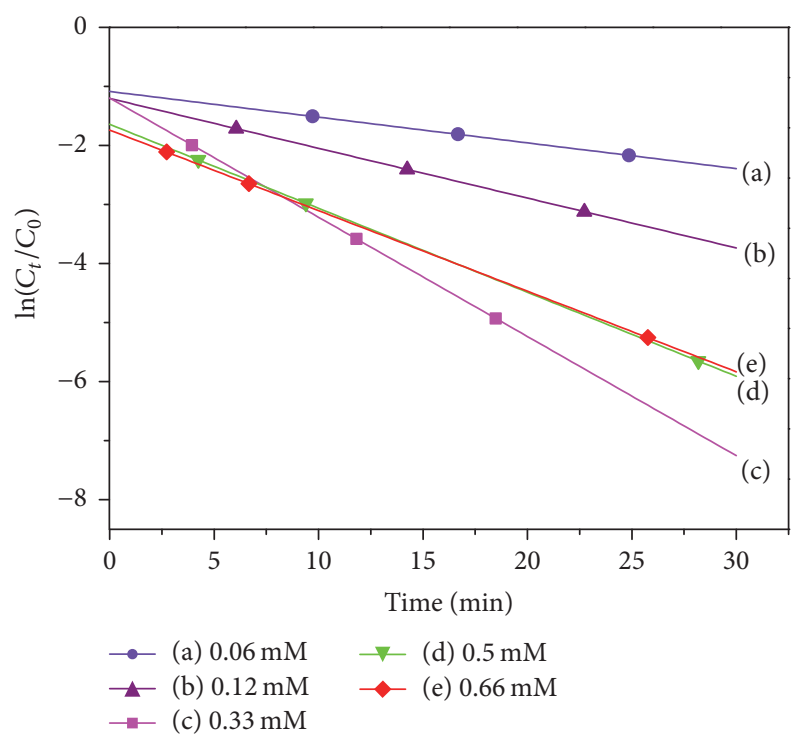

FIGURE 6: Kinetic for decomposition of bromothymol blue with GZVINPs concentration of (a) $0.06 \mathrm{mM}$, (b) $0.12 \mathrm{mM}$, (c) $0.33 \mathrm{mM}$, (d) $0.5 \mathrm{mM}$, and (e) $0.66 \mathrm{mM}$.

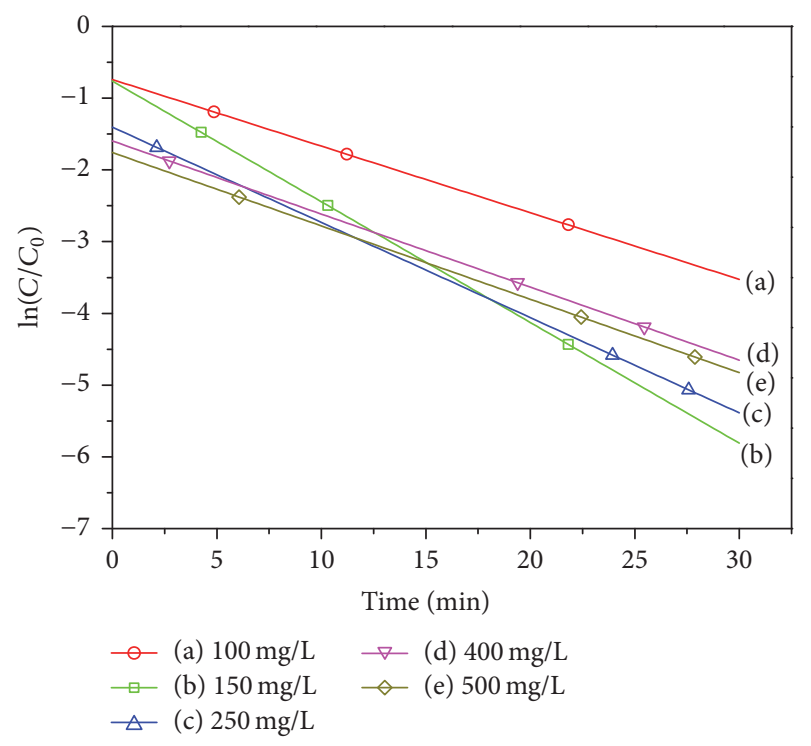

FIgURE 7: Kinetic for degradation of bromothymol blue with different concentration using $0.33 \mathrm{mM}$ GZVINPs.

within 15 min at ambient temperature, which is significantly superior to the result $(\sim 60 \mathrm{~min})$ in the reported study. And the catalytic kinetics indicate that the highest reaction rate was achieved in the presence of $2 \% \mathrm{H}_{2} \mathrm{O}_{2}$ and $0.33 \mathrm{mM}$ iron nanoparticles when the bromothymol blue is $150 \mathrm{mg} / \mathrm{L}$. The results convincingly demonstrate that the GZVINPs accelerated the catalytic conversion leading to the obvious increase of the degradation rate of bromothymol blue. Therefore, green nanotechnology will play an important role in the exploration and improvement of the catalytic degradation of dyeing effluents in the environment.
TABLE 2: Rates constants of degradation of bromothymol blue with different concentration using $0.33 \mathrm{mM}$ GZVINPs catalyzed $\mathrm{H}_{2} \mathrm{O}_{2}$.

\begin{tabular}{lccc}
\hline Curve in Figure 7 & $\begin{array}{c}\text { Bromothymol blue } \\
(\mathrm{mg} / \mathrm{L})\end{array}$ & $\begin{array}{c}\text { Rate } \\
\left(\mathrm{min}^{-1}\right)\end{array}$ & $R^{2}$ \\
\hline (a) & 100 & 0.09286 & 0.99721 \\
(b) & 150 & 0.16825 & 0.92986 \\
(c) & 250 & 0.13278 & 0.97113 \\
(d) & 400 & 0.10185 & 0.97786 \\
(e) & 500 & 0.10226 & 0.96533 \\
\hline
\end{tabular}

\section{Competing Interests}

The authors declare that there are no competing interests regarding the publication of this paper.

\section{Acknowledgments}

The authors thank the kind support of this work from the Natural Science Foundation of Fujian Province (no. 2012J05025), Research Foundation of Education Bureau of Fujian Province, China (JA15022), Xiamen Science and Technology Project (3502Z20163011), the Research Innovation Project of Graduate Students in Huaqiao University (2014), and the Key Projects of Science and Technology of Fujian (no. 2014N0006).

\section{References}

[1] F. Fu, M. Hu, B. Tang, W. Han, and Z. Cheng, "Removal of $\mathrm{Cr}(\mathrm{VI})$ from wastewater using acid-washed zero-valent iron catalyzed by polyoxometalate under acid conditions: efficacy, reaction mechanism and influencing factors," Journal of the Taiwan Institute of Chemical Engineers, vol. 47, pp. 177-181, 2015.

[2] R. Kumar, N. Singh, and S. N. Pandey, "Potential of green synthesized zero-valent iron nanoparticles for remediation of lead-contaminated water," International Journal of Environmental Science and Technology, vol. 12, no. 12, pp. 3943-3950, 2015.

[3] T. Wang, X. Jin, Z. Chen, M. Megharaj, and R. Naidu, "Green synthesis of $\mathrm{Fe}$ nanoparticles using eucalyptus leaf extracts for treatment of eutrophic wastewater," Science of the Total Environment, vol. 466-467, pp. 210-213, 2014.

[4] H. Abdul Salam, P. Rajiv, M. Kamaraj, P. Jagadeeswaran, S. Gunalan, and R. Sivaraj, "Plants: green route for nanoparticle synthesis," International Research Journal of Biological Sciences, vol. 1, no. 5, pp. 85-90, 2012.

[5] L. Huang, X. Weng, Z. Chen, M. Megharaj, and R. Naidu, "Green synthesis of iron nanoparticles by various tea extracts: comparative study of the reactivity," Spectrochimica Acta Part A: Molecular and Biomolecular Spectroscopy, vol. 130, pp. 295-301, 2014.

[6] L. Tong, M. Zhao, S. Zhu, and J. Chen, "Synthesis and application of superparamagnetic iron oxide nanoparticles in targeted therapy and imaging of cancer," Frontiers of Medicine, vol. 5, no. 4, pp. 379-387, 2011.

[7] M. Cao, Z. Li, J. Wang et al., "Food related applications of magnetic iron oxide nanoparticles: enzyme immobilization, protein purification, and food analysis," Trends in Food Science and Technology, vol. 27, no. 1, pp. 47-56, 2012. 
[8] G. K. Kouassi, "Magnetic and gold-coated magnetic iron oxide nanoparticles as detection tools: preparation, characterization, and biosensing applications," Current Nanoscience, vol. 7, no. 4, pp. 510-523, 2011.

[9] R. Singh, A. Singh, V. Misra, and R. P. Singh, "Degradation of lindane contaminated soil using zero-valent iron nanoparticles," Journal of Biomedical Nanotechnology, vol. 7, no. 1, pp. 175-176, 2011.

[10] R. A. Crane and T. B. Scott, "Nanoscale zero-valent iron: future prospects for an emerging water treatment technology," Journal of Hazardous Materials, vol. 211-212, pp. 112-125, 2012.

[11] E. Matei, A. Predescu, E. Vasile, and A. Predescu, "Properties of magnetic iron oxides used as materials for wastewater treatment," Journal of Physics: Conference Series, vol. 304, no. 1, 2011.

[12] G. Qiu, H. Huang, H. Genuino et al., "Microwave-assisted hydrothermal synthesis of nanosized $\alpha-\mathrm{Fe}_{2} \mathrm{O}_{3}$ for catalysts and adsorbents," Journal of Physical Chemistry C, vol. 115, no. 40, pp. 19626-19631, 2011.

[13] X. Weng, L. Huang, Z. Chen, M. Megharaj, and R. Naidu, "Synthesis of iron-based nanoparticles by green tea extract and their degradation of malachite," Industrial Crops and Products, vol. 51, pp. 342-347, 2013.

[14] K. M. Kumar, B. K. Mandal, K. S. Kumar, P. S. Reddy, and B. Sreedhar, "Biobased green method to synthesise palladium and iron nanoparticles using Terminalia chebula aqueous extract," Spectrochimica Acta Part A: Molecular and Biomolecular Spectroscopy, vol. 102, pp. 128-133, 2013.

[15] K. B. Narayanan and N. Sakthivel, "Biological synthesis of metal nanoparticles by microbes," Advances in Colloid and Interface Science, vol. 156, no. 1-2, pp. 1-13, 2010.

[16] O. V. Kharissova, H. V. R. Dias, B. I. Kharisov, B. O. Pérez, and V. M. J. Pérez, “The greener synthesis of nanoparticles," Trends in Biotechnology, vol. 31, no. 4, pp. 240-248, 2013.

[17] X.-Q. Li, D. W. Elliott, and W.-X. Zhang, "Zero-valent iron nanoparticles for abatement of environmental pollutants: materials and engineering aspects," Critical Reviews in Solid State and Materials Sciences, vol. 31, no. 4, pp. 111-122, 2006.

[18] T. Shahwan, S. Abu Sirriah, M. Nairat et al., "Green synthesis of iron nanoparticles and their application as a Fenton-like catalyst for the degradation of aqueous cationic and anionic dyes," Chemical Engineering Journal, vol. 172, no. 1, pp. 258-266, 2011.

[19] D. O'Carroll, B. Sleep, M. Krol, H. Boparai, and C. Kocur, "Nanoscale zero valent iron and bimetallic particles for contaminated site remediation," Advances in Water Resources, vol. 51, pp. 104-122, 2013.

[20] O. V. Kharissova and B. I. Kharisov, "Synthetic techniques and applications of activated nanostructurized metals: highlights up to 2008," Recent Patents on Nanotechnology, vol. 2, no. 2, pp. 103119, 2008.

[21] Z. C. Zhuang, L. L. Huang, F. F. Wang, and Z. L. Chen, "Effects of cyclodextrin on the morphology and reactivity of iron-based nanoparticles using Eucalyptus leaf extract," Industrial Crops and Products, vol. 69, pp. 308-313, 2015.

[22] Y. Cai, Y. Shen, A. Xie, S. Li, and X. Wang, "Green synthesis of soya bean sprouts-mediated superparamagnetic $\mathrm{Fe}_{3} \mathrm{O}_{4}$ nanoparticles," Journal of Magnetism and Magnetic Materials, vol. 322, no. 19, pp. 2938-2943, 2010.

[23] Y.-P. Sun, X.-Q. Li, W.-X. Zhang, and H. P. Wang, "A method for the preparation of stable dispersion of zero-valent iron nanoparticles," Colloids and Surfaces A: Physicochemical and Engineering Aspects, vol. 308, no. 1-3, pp. 60-66, 2007.

[24] S. Mohanraj, S. Kodhaiyolii, M. Rengasamy, and V. Pugalenthi, "Green synthesized iron oxide nanoparticles effect on fermentative hydrogen production by Clostridium acetobutylicum," Applied Biochemistry and Biotechnology, vol. 173, no. 1, pp. 318331, 2014.

[25] Y. Li, G. Li, W. Li, F. Yang, and H. Liu, "Greenly synthesized goldalginate nanocomposites catalyst for reducing decoloration of azo-dyes," Nano, vol. 10, no. 8, Article ID 1550108, 2015.

[26] S. Sohrabnezhad, M. Rassa, and A. Seif,, "Green synthesis of Ag nanoparticles in montmorillonite," Materials Letters, vol. 168, pp. 28-30, 2016.

[27] F. Torkamani and S. Azizian, "Green and simple synthesis of Ag nanoparticles loaded onto cellulosic fiber as efficient and low-cost catalyst for reduction of 4-nitrophenol," Journal of Molecular Liquids, vol. 214, pp. 270-275, 2016.

[28] Y. Zhang, X. Bo, A. Nsabimana et al., "Green and facile synthesis of an Au nanoparticles at polyoxometalate/ordered mesoporous carbon tri-component nanocomposite and its electrochemical applications," Biosensors and Bioelectronics, vol. 66, pp. 191-197, 2015.

[29] W. Yan, C. Chen, L. Wang et al., "Facile and green synthesis of cellulose nanocrystal-supported gold nanoparticles with superior catalytic activity," Carbohydrate Polymers, vol. 140, pp. 66-73, 2016.

[30] R. Wang, Y. Yao, M. Shen, and X. Wang, "Green synthesis of Au@Ag nanostructures through a seed-mediated method and their application in SERS," Colloids and Surfaces A: Physicochemical and Engineering Aspects, vol. 492, pp. 263-272, 2016.

[31] A. Annamalai, V. L. P. Christina, D. Sudha, M. Kalpana, and P. T. V. Lakshmi, "Green synthesis, characterization and antimicrobial activity of Au NPs using Euphorbia hirta L. leaf extract," Colloids and Surfaces B: Biointerfaces, vol. 108, pp. 6065, 2013.

[32] S. Ahmed, M. Ahmad, B. L. Swami, and S. Ikram, "Green synthesis of silver nanoparticles using Azadirachtaindica aqueous leaf extract," Journal of Radiation Research and Applied Sciences, vol. 9, no. 1, pp. 1-7, 2016.

[33] S. S. Shankar, A. Ahmad, R. Pasricha, and M. Sastry, "Bioreduction of chloroaurate ions by geranium leaves and its endophytic fungus yields gold nanoparticles of different shapes," Journal of Materials Chemistry, vol. 13, no. 7, pp. 1822-1826, 2003.

[34] S. S. Shankar, A. Rai, B. Ankamwar, A. Singh, A. Ahmad, and M. Sastry, "Biological synthesis of triangular gold nanoprisms," Nature Materials, vol. 3, no. 7, pp. 482-488, 2004.

[35] J. Huang, Q. Li, D. Sun et al., "Biosynthesis of silver and gold nanoparticles by novel sundried Cinnamomum camphora leaf," Nanotechnology, vol. 18, no. 10, Article ID 105104, 2007.

[36] J. Huang, L. Lin, Q. Li et al., "Continuous-flow biosynthesis of silver nanoparticles by lixivium of sundried cinnamomum camphora leaf in tubular microreactors," Industrial \& Engineering Chemistry Research, vol. 47, no. 16, pp. 6081-6090, 2008.

[37] X. Yang, Q. Li, H. Wang et al., "Green synthesis of palladium nanoparticles using broth of Cinnamomum camphora leaf," Journal of Nanoparticle Research, vol. 12, no. 5, pp. 1589-1598, 2010.

[38] G. Kozma, A. Rónavári, Z. Kónya, and Á. Kukovecz, "Environmentally benign synthesis methods of zero-valent iron nanoparticles," ACS Sustainable Chemistry and Engineering, vol. 4, no. 1, pp. 291-297, 2016. 
[39] G. E. Hoag, J. B. Collins, J. L. Holcomb, J. R. Hoag, M. N. Nadagouda, and R. S. Varma, "Degradation of bromothymol blue by 'greener' nano-scale zero-valent iron synthesized using tea polyphenols," Journal of Materials Chemistry, vol. 19, no. 45, pp. 8671-8677, 2009.

[40] L. Huang, X. Weng, Z. Chen, M. Megharaj, and R. Naidu, "Synthesis of iron-based nanoparticles using oolong tea extract for the degradation of malachite green," Spectrochimica ActaPart A: Molecular and Biomolecular Spectroscopy, vol. 117, pp. 801-804, 2014. 

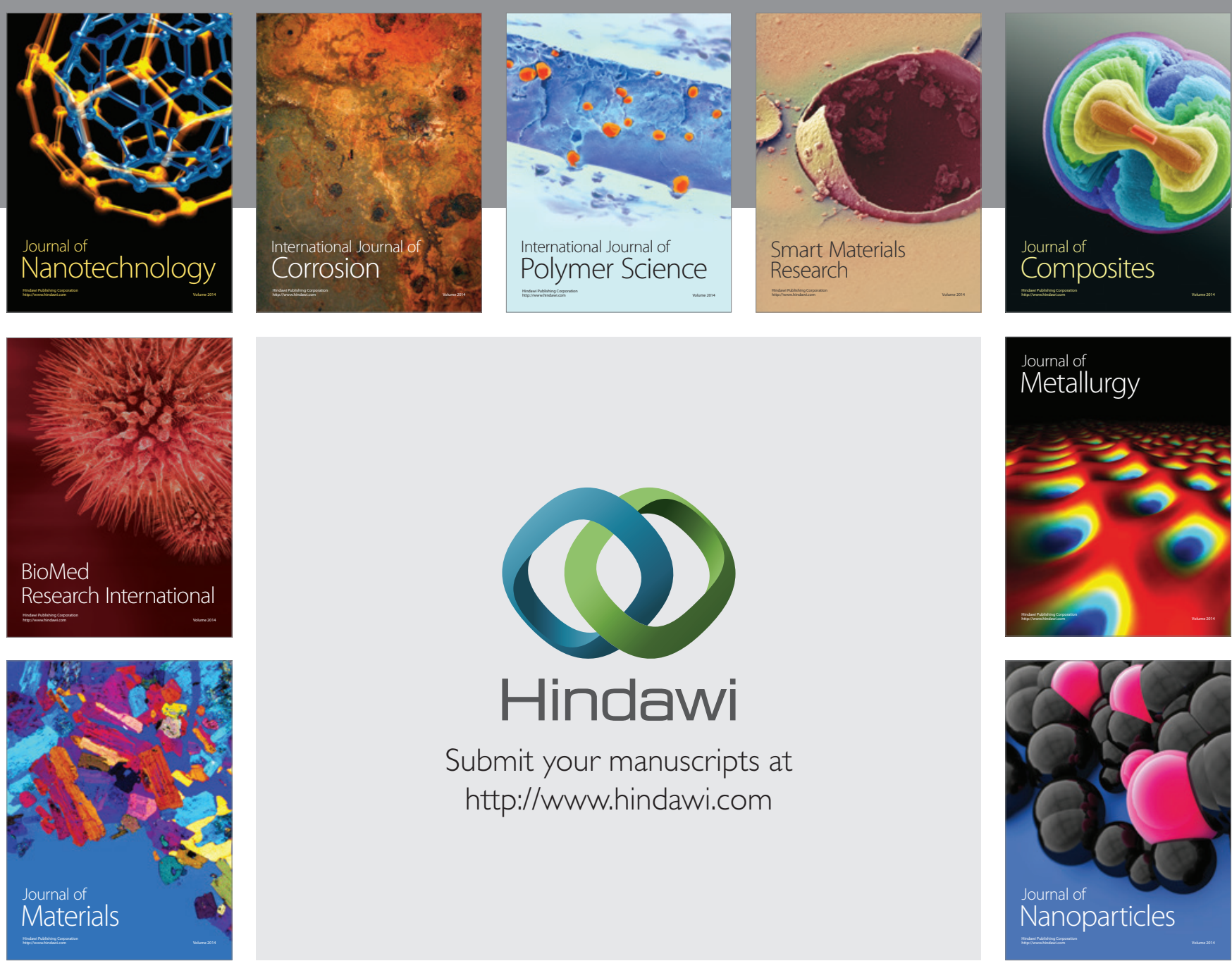

\section{Hindawi}

Submit your manuscripts at

http://www.hindawi.com

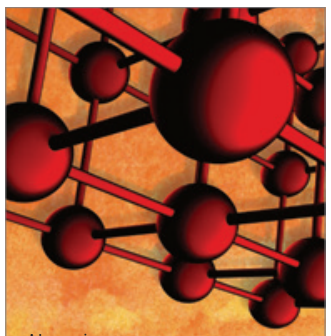

Materials Science and Engineering
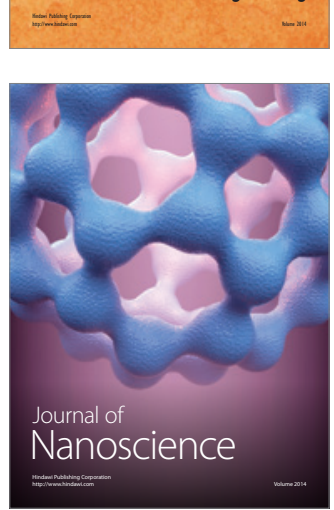
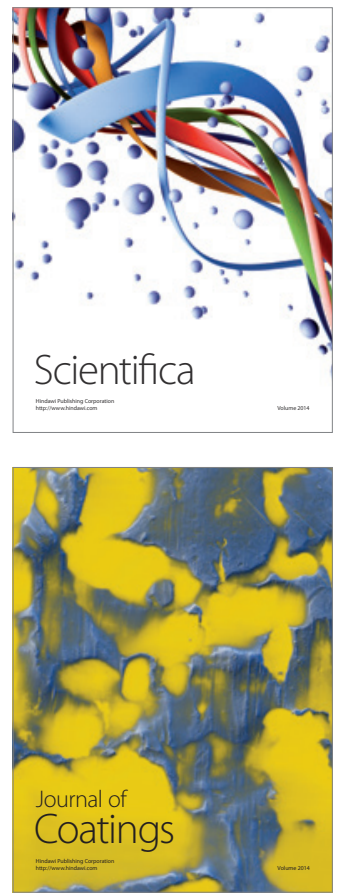
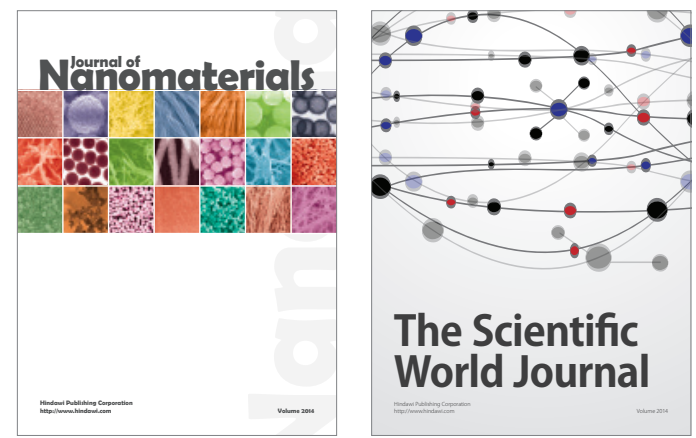

The Scientific World Journal
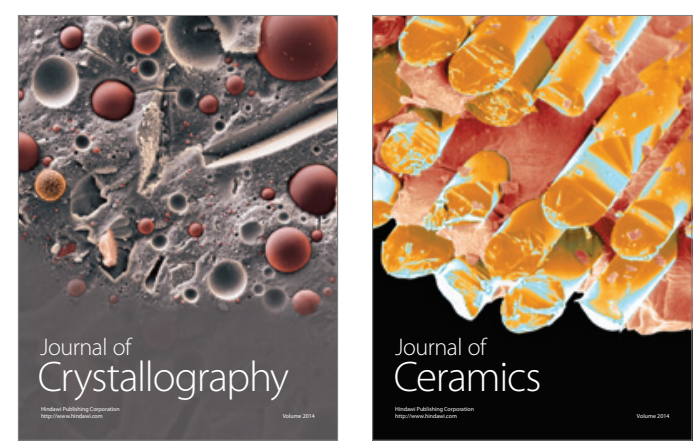
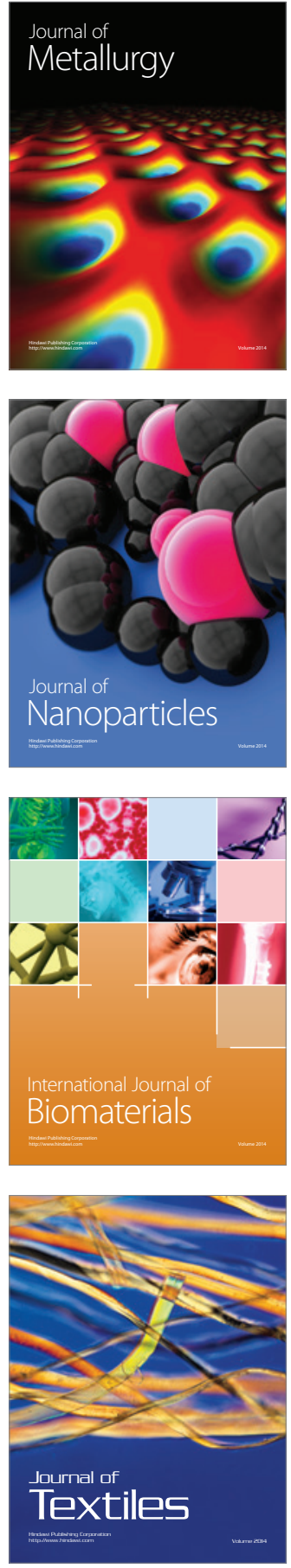